\title{
Everything's Greener on the Other Graphene
}<smiles>Nc1c(N)c(Br)c(Br)c(Br)c1O</smiles>

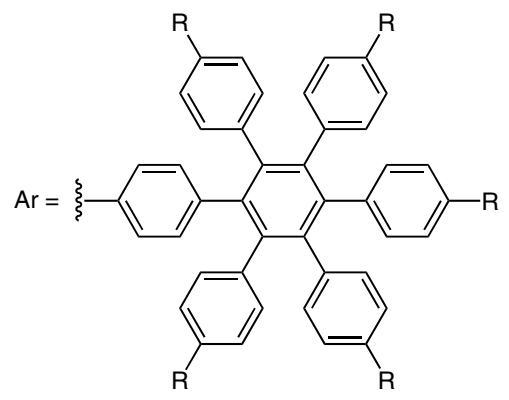

\section{Key words}

nanographene

Scholl cyclization

polycyclic aromatic hydrocarbon

$$
\begin{aligned}
& \text { 1. DDQ, TfOH, } \mathrm{CH}_{2} \mathrm{Cl}_{2} \\
& 92 \% \text { yield }
\end{aligned}
$$

2. $\mathrm{DDQ}, \mathrm{MeSO}_{3} \mathrm{H}, \mathrm{CH}_{2} \mathrm{Cl}_{2}$

$65 \%$ yield

$\mathrm{R}=t-\mathrm{Bu}$

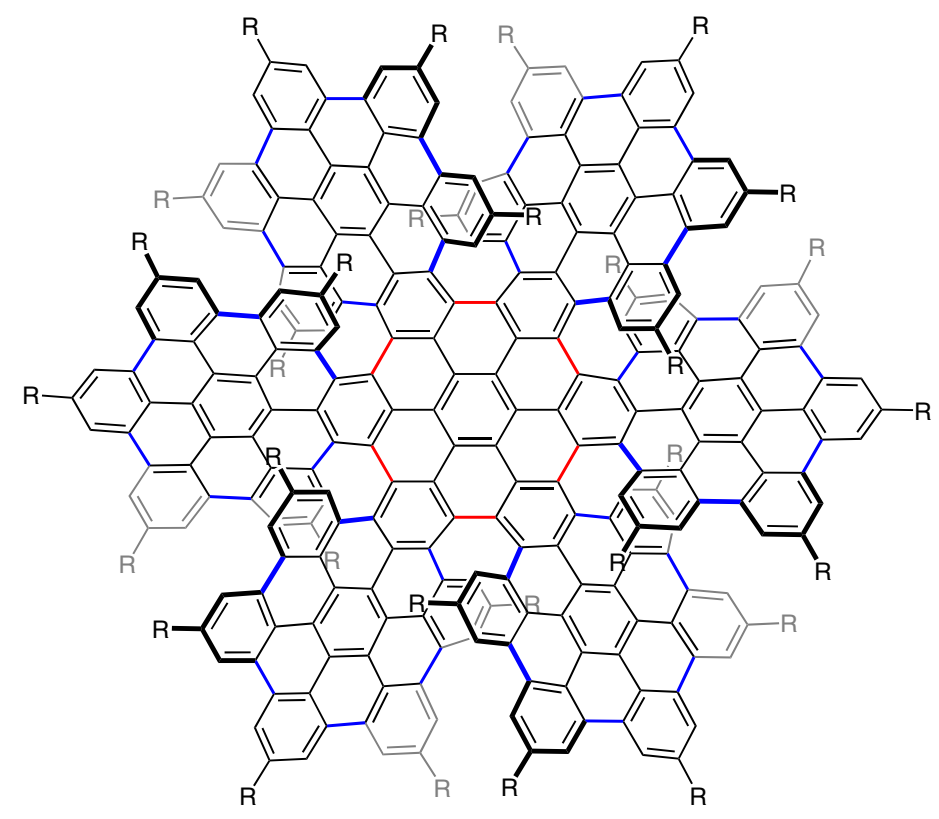

Significance: The synthesis of large graphene model systems becomes more difficult as the size of the system increases, due both to issues in solubility and efficiency of reactions. In this report, Wang and co-workers present a scalable, efficient route to make a green graphene nano propeller that represents the largest 3-D, fully conjugated polycyclic aromatic hydrocarbon prepared by solution chemistry to date.
Comment: The nano propeller is soluble in most common organic solvents, allowing for solutionphase characterization. The compound has strong UV/Vis and near IR absorption and rich electrochemistry. The structure was confirmed with X-ray crystallography, and resolution of enantiomers was enabled by chiral HPLC. CD spectroscopy revealed the strongest Cotton effect in the visible region for a synthetic complex observed to date. 